\title{
Single Loop Electrochemical Potentiokinetic Reactivation Behaviour of Continuously Cooled SUS329J4L Duplex Stainless Steel
}

\section{Rongguang Wang ${ }^{{ }^{*}}$, Masanobu Imagawa ${ }^{2}$, Masaharu Honda ${ }^{3}$ and Hideki Fukuhara ${ }^{4}$}

${ }^{1}$ Department of Mechanical Systems Engineering, Hiroshima Institute of Technology, 2-1-1 Miyake, Saeki-ku, Hiroshima, 731-5193, Japan

${ }^{2}$ Graduate School of Science and Technology, Hiroshima Institute of Technology, 2-1-1 Miyake, Saeki-Ku, Hiroshima 731-5193, Japan

${ }^{3}$ Nikko Techno Co., Ltd, 1-6-1 Funakoshiminami, Aki-ku, Hiroshima, 736-8602, Japan

${ }^{4}$ The Japan Steel Works, Ltd., 1-6-1 Funakoshiminami, Aki-ku, Hiroshima, 736-8602, Japan

\begin{abstract}
Sigma phase precipitates in duplex stainless steel during slow cooling from high temperature, which generally induces great loss in both corrosion resistance and impact toughness. To develop a nondestructive method for detecting the presence of sigma phase in duplex stainless steel for on-site use in the quality management of ready-made large machines, the single loop electrochemical potentiokinetic reactivation (SL-EPR) behaviour of SUS329J4L duplex stainless steel continuously cooled from the solution annealing temperature with various rates by adjusting fluxes of cool nitrogen gas were investigated under several polarization conditions. The reactivation current density of SL-EPR test was used to detect the precipitated $\sigma$ phase and compared with the ferric chloride test, the modified DL-EPR test and the impact test, as well as observation of the dissolution morphology. As the result, the high reactivation current density in the SL-EPR polarization was obtained on the cooled SUS329J4L steel at WQ $~ 0.02$ $\mathrm{K} / \mathrm{s}$ in solution of $0.5 \mathrm{M} \mathrm{H}_{2} \mathrm{SO}_{4}+0.01 \mathrm{M} \mathrm{KSCN}+0.5 \mathrm{M} \mathrm{NaCl}$ at potential sweep rate of $0.83 \mathrm{mV} / \mathrm{s}$. In the polarization, the potential holding at $0.3 \mathrm{~V}$ vs. SCE for $300 \mathrm{~s}$ before sweeping the potential to negative side is necessary to stabilize the passive film and thus improved the detection sensitivity of sigma phase in duplex stainless steel. As comparison, the modified SL-EPR test which checks the presence of sigma phase has a quasi-equivalent detection sensitivity to impact test on the WQ $\sim 0.02 \mathrm{~K} / \mathrm{s}$ cooled SUS329J4L steel, with higher sensitivity in SL-EPR method than the modified DL-EPR method.
\end{abstract}

Publication History:

\section{Introduction}

The duplex stainless steels comprising austenite $(\gamma)$ and ferrite $(\alpha)$ phases are widely utilized in many industrial fields because of their high corrosion resistance and excellent mechanical properties. On the other hand, the sigma $(\sigma)$ phase, which contains high concentration of chromium ( $\mathrm{Cr}$ ) and molybdenum(Mo) with two inner quasihexagonal layers in a 30-atom tetragonal crystal lattice [1-4], generally precipitates in the a phase when the steel is isothermally aged between $973 \sim 1173 \mathrm{~K}$ [5-12] or is slowly cooled from a near solution annealing temperature $[13,14]$. This usually causes great loss in impact toughness because $\sigma$ phase causes easier cleavage fracture[4-8] and the decrease in corrosion resistance due to the depletion of $\mathrm{Cr}$ and Mo in vicinity to $\sigma$ phase $[8,15,16]$. It has been known that both the Charpy impact energy and corrosion resistance in ferric chloride solution of slowly cooled 2205 duplex stainless steel after annealed at $1338 \mathrm{~K}$ were degraded [17]. In particular, the cooling process from a high temperature is inevitable in either of fabricating mill-products or machines, therefore it is important to have a non-destructive and effective way to on-site detect the precipitated $\sigma$ phase in duplex steel for lowering manufacture and maintenance cost in the quality management.

It is no doubt that the metallographic examination after electrolytic etching in sodium hydroxide or oxalic acid is the traditional and exact way to detect the presence of $\sigma$ phase. However, it is difficult to quantify the observation. Other methods, such as the impact test and the ferric chloride test, are casually considered useful to detect the absence of harmful level of $\sigma$ and other intermetallic phases $[18,19]$. The authors revealed that the Charpy absorbed energy obtained from a sub-size impact test at room temperature is much more sensitive than the ferric chloride test in $6.0 \mathrm{wt} . \% \mathrm{FeCl}_{3}$ solution, in instantly responding to the minute change of $\sigma$ phase precipitation despite the method's destructivity [19]. On the other hand, the double loop electrochemical potentiokinetic reactivation (DL-EPR) ratio responds to the decomposition of $a$ phase to intermetallic compounds of $\sigma$ phase and carbides as well as $\chi$ phase with vicinity to Cr- or Modepleted regions [7,9,20-22]. This electrochemical method can be onsite applied on ready-made large machines by using a portable or a disposable electrochemical mini cell as a non-destructive test. Lopez et al. obtained a result that the DL-EPR ratio seemed proportional to $\sigma$ phase content in duplex stainless steel of UNS S31803 in a solution containing $0.01 \mathrm{M} \mathrm{KSCN}+2 \mathrm{M} \mathrm{H}_{2} \mathrm{SO}_{4}+0.5 \mathrm{M} \mathrm{NaCl}$ [20]. The authors also recently developed a modified DL-EPR method to detect $\sigma$ phase in SUS329J4L steel at average cooling rates of 1.0 to $0.02 \mathrm{~K} / \mathrm{s}$ from 1073 to $773 \mathrm{~K}$, in a solution of $0.5 \mathrm{M} \mathrm{H}_{2} \mathrm{SO}_{4}+0.01 \mathrm{M} \mathrm{KSCN}+0.5 \mathrm{M} \mathrm{NaCl}$. However, the DL-EPR ratios were too small to be distinguished on the steels cooled at $0.3 \mathrm{~K} / \mathrm{s}$ and higher, with minute amount of $\sigma$ phase [23]. It should be related to the occurring of local active corrosion and the unstable passive film formed in the forward polarization [24,25], however, this had not been checked on the SUS329J4L steel. If it is true, the detection sensitivity for $\sigma$ phase should be enhanced by using the single loop electrochemical potentiokinetic reactivation (SL-EPR) test, in which the potential is directly swept from a passive potential to the reactive potential avoiding the undesired prior local dissolution $[24,25]$.

"Corresponding Author: Prof. Rongguang Wang, Department of Mechanical Systems Engineering, Hiroshima Institute of Technology, 2-1-1 Miyake, Saeki-ku, Hiroshima, 731-5193, Japan; E-mail: wangrg@cc.it-hiroshima.ac.jp

Citation: Wang R, Imagawa M, Honda M, Fukuhara H (2017) Single Loop Electrochemical Potentiokinetic Reactivation Behaviour of Continuously Cooled SUS329J4L Duplex Stainless Steel. Int J Mech Syst Eng 3: 125. https://doi. org/10.15344/2455-7412/2017/125

Copyright: () 2017 Wang et al. This is an open-access article distributed under the terms of the Creative Commons Attribution License, which permits unrestricted use, distribution, and reproduction in any medium, provided the original author and source are credited. 
Citation: Wang R, Imagawa M, Honda M, Fukuhara H (2017) Single Loop Electrochemical Potentiokinetic Reactivation Behaviour of Continuously Cooled SUS329J4L Duplex Stainless Steel. Int J Mech Syst Eng 3: 125. https://doi.org/10.15344/2455-7412/2017/125

Page 2 of 7

Here in this study, the SUS329J4L duplex stainless steel was respectively cooled at several different cooling rates from the solution annealing temperature. The observation of specimen surface after the forward and then the backward polarizations of DL-EPR test was conducted to check the prior local dissolution and its affection on the reactivation behaviour. After then, the SL-EPR test was carried out on the cooled steel under various polarization conditions. The reactivation current density of SL-EPR test was used to detect the precipitated $\sigma$ phase and compared with the ferric chloride test, the modified DLEPR test and the impact test, as well as observation of the dissolution morphology. Finally, the optimum measurement condition of SL-EPR was chosen for obtaining high detection sensitivity of $\sigma$ phase.

\section{Experimental}

\section{Material and heat treatment}

A commercially supplied SUS329J4L duplex stainless steel bar with chemical composition shown in Table 1 was used in this work. The steel bar was cut to specimens of $20 \mathrm{~mm}$ x $20 \mathrm{~mm}$ with thickness of 5 $\mathrm{mm}$ and then heat treated in vacuum furnace, being aged at $1323 \mathrm{~K}$ for $1.8 \mathrm{ks}$ followed with continuously cooling to room temperature. Except water quenching (WQ), several averaged cooling rates of 1.0, $0.5,0.3,0.2,0.1,0.02 \mathrm{~K} / \mathrm{s}$ within 1073 and $773 \mathrm{~K}$ were applied by adjusting fluxes of coolnitrogen gas. The specimen was then polished by 2000 grit paper followed with ultrasonic cleaning in acetone. Note that the averaged cooling rate used here, with slower value in slower cooling process, is not a representative parameter to indicate the convection cooling. The authors expect to modify it with considering its relation to the precipitation state of $\sigma$ phase in the future work. Prior to all the EPR polarization, the specimen surface was sealed with silicone sealant leaving an exposed area of about $100 \mathrm{~mm}^{2}$.

\section{DL-EPR test and surface observation}

In both the DL-EPR and the SL-EPR, the polarization was performed in a typical three-electrode electrochemical cell, with a platinum plate as counter electrode and a saturated calomel electrode (SCE) as reference electrode. The electrochemical cell was put into water bath to keep the solution at constant temperature of $303 \pm 2 \mathrm{~K}$. The solutions with different concentrations of $\mathrm{NaCl}$ in $0.5 \mathrm{M} \mathrm{H}_{2} \mathrm{SO}_{4}$ $+0.01 \mathrm{M} \mathrm{KSCN}$ were deaerated by nitrogen gas for $1.8 \mathrm{ks}$ before and during the test.

In the DL-EPR test, the $0.02 \mathrm{~K} / \mathrm{s}$ cooled specimen surfaces were observed after the potential was swept at sweep rate of $0.83 \mathrm{mV} / \mathrm{s}$ to $0.3 \mathrm{~V}$ (vs. SCE) in passive zone and then backward to $-0.3 \mathrm{~V}$ corresponding to the reactivation current peak in the above solution.

\section{SL-EPR test}

In the SL-EPR test, the specimen was kept at the open circuit potential (OCP) for $300 \mathrm{~s}$, following with a cathodic polarization at $-1.0 \mathrm{~V}$ for $60 \mathrm{~s}$ and again kept at the OCP for $300 \mathrm{~s}$. After further a cathode polarization from $-0.6 \mathrm{~V}$ to OCP, the polarization started at potential sweep rate of $0.83 \mathrm{mV} / \mathrm{s}$ from $0.3 \mathrm{~V}$ to $-0.6 \mathrm{~V}$, as shown in Table 2 under the condition of SL-EPR (1). On the other hand, under the condition of SL-EPR (2), the potential was kept at $0.3 \mathrm{~V}$ for
$300 \mathrm{~s}$ before sweeping to $-0.6 \mathrm{~V}$. The cathodic polarizations at $-1.0 \mathrm{~V}$ and from $-0.6 \mathrm{~V}$ to OCP aim to obtain a bare surface without passive film before sweeping the potential backward reactive zone. Figure 1 shows a schematic SL-EPR curve, where $I_{R}$ is the peak of reactivation current density corresponding to corrosion from $\mathrm{Cr}$ - or Mo-depleted regions around $\sigma$ phase. The reactivation current density of $I_{\mathrm{R}}$ but not the normalized charge $[24,26]$ was used as a simple way to express the reactive dissolution with consideration of the difficulty to obtain the real grain boundary area around $\sigma$ phase. After polarization, the specimen surfaces were observed with scanning electron microscope (SEM).

\begin{tabular}{|c|c|c|c|c|}
\hline & \multicolumn{3}{|c|}{ Concentration of solutions } & \multirow{2}{*}{$\begin{array}{c}\text { Scanning Rate } \\
(\mathrm{mV} / \mathrm{s})\end{array}$} \\
\hline & $\mathrm{H}_{2} \mathrm{SO}_{4}$ & $\mathrm{KSCN}(\mathrm{M})$ & $\mathrm{NaCl}(\mathrm{M})$ & \\
\hline \multirow{4}{*}{ SL-EPR(1) } & 0.5 & 0.01 & 0 & 0.833 \\
\hline & 0.5 & 0.01 & 0.2 & 0.833 \\
\hline & 0.5 & 0.01 & 0.3 & 0.833 \\
\hline & 0.5 & 0.01 & 0.5 & 0.833 \\
\hline Sl-EPR(2) & 0.5 & 0.01 & 0.5 & 0.833 \\
\hline
\end{tabular}

Table 2: Various conditions used in SL-EPR polarization.

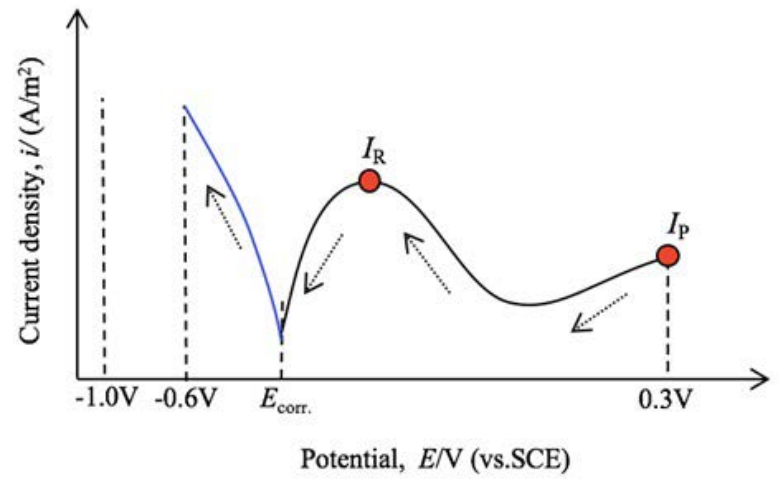

Figure 1: Schematic polarization drawing of SL-EPR curve with indicators of passive current density of $I_{p}$ and reactivation current density of $I_{R}$.

\section{Results and Discussion}

\section{Surface observation in DL-EPR process}

In isothermal aging of duplex stainless steel, it had been known that $\sigma$ phase precipitates as follows [9]. Chromium carbides $\left(\mathrm{M}_{23} \mathrm{C}_{6}\right)$ precipitate in $\gamma$ phase near the $\gamma / \alpha$ boundary and grow into a phase associated with the formation of new $\gamma^{\prime}$. The new $\gamma^{\prime}$ phase contains less $\mathrm{Cr}$ and Mo than the original $\gamma$ phase. $\sigma$ phase nucleated at the $\mathrm{M}_{23} \mathrm{C}_{6} / \gamma^{\prime}$ interface and then grow into $\alpha$ phase with the continuous precipitation of new $y$ ' phase. During such precipitation, Cr- or Mo-depleted region formed around $\sigma$ phase $[13,27]$. The same precipitation should also occur in the slow cooling of SUS329J4L steel. In the previous XRD analysis, about $22.9 \% \sigma$ phase was detected in the $0.02 \mathrm{~K} / \mathrm{s}$ cooled SUS329J4L steel [23].

\begin{tabular}{|l|l|l|l|l|l|l|l|l|l|l|}
\hline & $\mathrm{C}$ & $\mathrm{Si}$ & $\mathrm{Mn}$ & $\mathrm{P}$ & $\mathrm{S}$ & $\mathrm{Ni}$ & $\mathrm{Cr}$ & Mo & $\mathrm{N}$ & $\mathrm{Fe}$ \\
\hline SUS329J4L & 0.029 & 0.43 & 0.73 & 0.038 & $<0.005$ & 5.68 & 24.19 & 2.68 & 0.14 & Bal. \\
\hline
\end{tabular}

Table 1: Chemical composition of SUS329J4L duplex stainless steel (wt.\%). 
Citation: Wang R, Imagawa M, Honda M, Fukuhara H (2017) Single Loop Electrochemical Potentiokinetic Reactivation Behaviour of Continuously Cooled SUS329J4L Duplex Stainless Steel. Int J Mech Syst Eng 3: 125. https://doi.org/10.15344/2455-7412/2017/125

Page 3 of 7

Figure 2 shows the $0.02 \mathrm{~K} / \mathrm{s}$ cooled specimen surfaces after the forward polarization to $0.3 \mathrm{~V}$ in passive zone (Figure $2(\mathrm{~b})$ ) and then the backward polarization to $-0.3 \mathrm{~V}$ corresponding to reactive zone (Figure $2(\mathrm{c})$ ). $\sigma$ phase can be seen at the potential of $0.3 \mathrm{~V}$ (Figure 2 (b)), indicating the prior dissolution of Cr- or Mo-depleted regions during the active zone [28] and accordingly the decrease of total area of such regions. This phenomenon should have directly resulted in the small reactivation current density and thus the undistinguishable small EPR ratio. Indeed, as shown in Figure 2 (c), further dissolution around $\sigma$ phase was not obvious, but some pits appeared in the $\gamma^{\prime}$ phase.

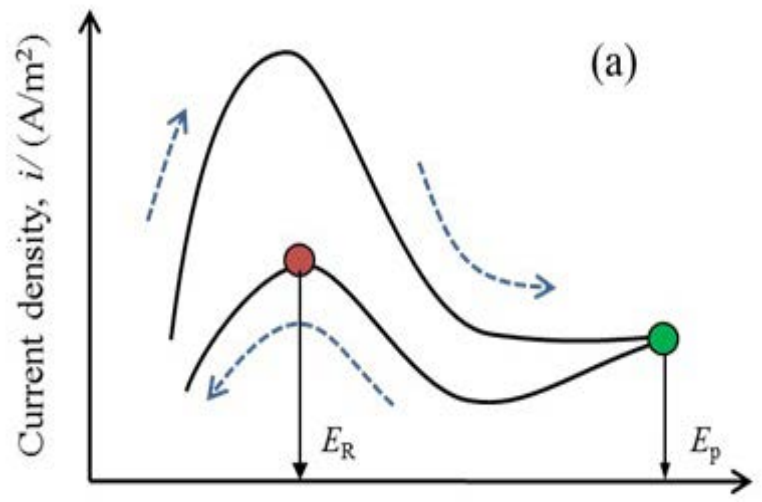

Potential, $E / V$ (vs.SCE)

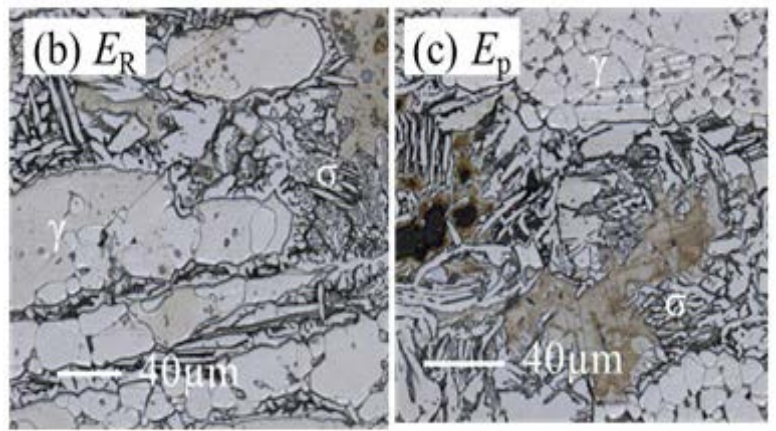

Figure 2 : Schematic DL-EPR polarization curve (a), and specimen surfaces after the potential reached $E_{\mathrm{p}}=300 \mathrm{mV}$ (vs. SCE) in passive zone (b) and the $E_{\mathrm{R}}=-300 \mathrm{mV}$ (vs. SCE) corresponding to the reactivation current peak (c) in solution of $0.5 \mathrm{M} \mathrm{H}_{2} \mathrm{SO}_{4}+0.01 \mathrm{M} \mathrm{KSCN}$ $+0.5 \mathrm{M} \mathrm{NaCl}$. The specimen was continuously cooled at $0.02 \mathrm{~K} / \mathrm{s}$.

Polarization curves and reactivationcurrent density of steel cooled at $0.3 \mathrm{~K} / \mathrm{s}$

In the previous report [23], the following had been clarified. In XRD analysis, about $5.9 \% \sigma$ phase was detected in the $0.2 \mathrm{~K} / \mathrm{s}$ cooled specimen whereas no discriminable $\sigma$ phase diffraction peaks can be found from specimens being cooled at $0.3 \mathrm{~K} / \mathrm{s}$ and higher. On the other hand, the absorbed energy of the sub-size specimens in the Charpy impact test at temperature kept nearly decreasing with the cooling rate from 1.0 to $0.02 \mathrm{~K} / \mathrm{s}$. The absorbed energy of $1.0 \mathrm{~K} / \mathrm{s}$ cooled specimen was almost the same with that of the water quenched specimen. Such results indicate that, (1) $\sigma$ phase can precipitate at cooling rates less than $1.0 \mathrm{~K} / \mathrm{s}$, and (2) higher $\sigma$ phase detection sensitivity can be obtained by impact test than by modified DL-EPR. In addition, the detection sensitivity by the modified DL-EPR is almost the same with XRD analysis in the authors' condition.
In the following, the specimen cooled at $0.3 \mathrm{~K} / \mathrm{s}$, in which $\sigma$ phase cannot be detected in the present XRD condition and the modified DL-EPR method but with obvious loss in absorbed energy, were used firstly to check the effectivity of various SL-EPR polarization conditions.

\section{Influence of $\mathrm{NaCl}$ concentration}

Figure 3 shows the polarization curves obtained on the $0.3 \mathrm{~K} / \mathrm{s}$ cooled specimen in solutions of $0.5 \mathrm{M} \mathrm{H}_{2} \mathrm{SO}_{4}+0.01 \mathrm{M} \mathrm{KSCN}+\mathrm{x}(0$ $\sim 0.5) \mathrm{M} \mathrm{NaCl}$ under the condition of SL-EPR (1). At the potential of $0.3 \mathrm{~V}$, the passive current density sharply reduced with the decrease in potential, indicating the formation of passive film on the bare substrate followed the prior cathode reduction processes. In solution without $\mathrm{NaCl}$ (Figure 3(a)), the reactivation current peak did not appear on the polarization curve. However, several current noises can be found at potentials ranging from -0.22 to $-0.3 \mathrm{~V}$, indicating a sign of much weak reactivation tendency. When $\mathrm{NaCl}$ concentration was $0.2 \mathrm{M}$ and higher, the reactivation current density peak clearly appeared and increased with $\mathrm{NaCl}$ concentration. The obtained reactivation current density $I_{\mathrm{R}}$ is shown in Figure 4. The increased values of $I_{\mathrm{R}}$ should be
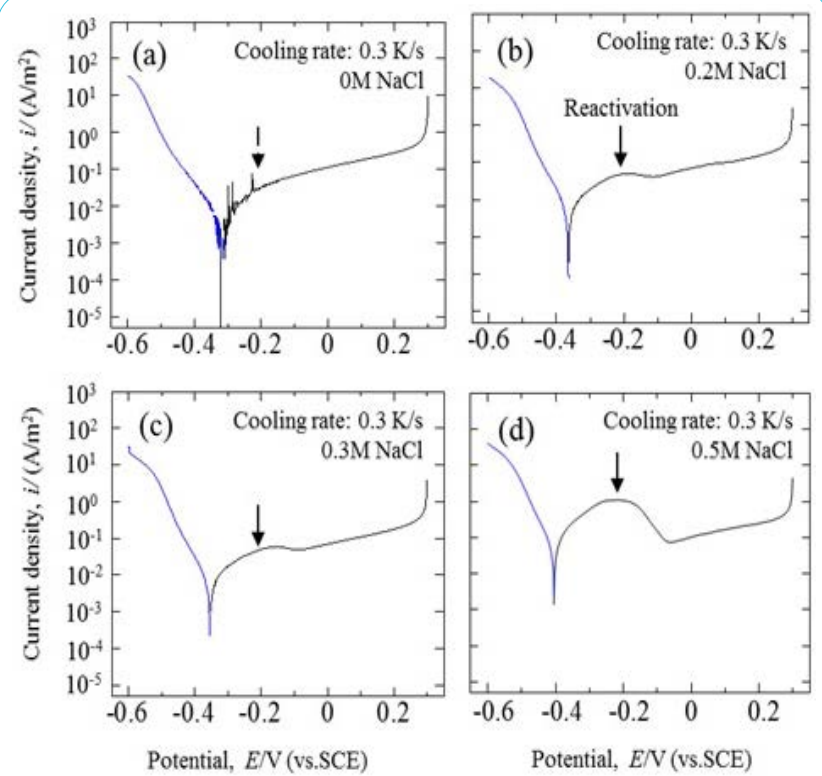

Figure 3: SL-EPR polarization curves of steel (cooling rate: $0.3 \mathrm{~K} / \mathrm{s}$ ) obtained in $0.5 \mathrm{M} \mathrm{H}_{2} \mathrm{SO}_{4}+0.01 \mathrm{M} \mathrm{KSCN}+\mathrm{x}(0 \sim 0.5) \mathrm{M} \mathrm{NaCl}$ solutions under the condition of SL-EPR (1).

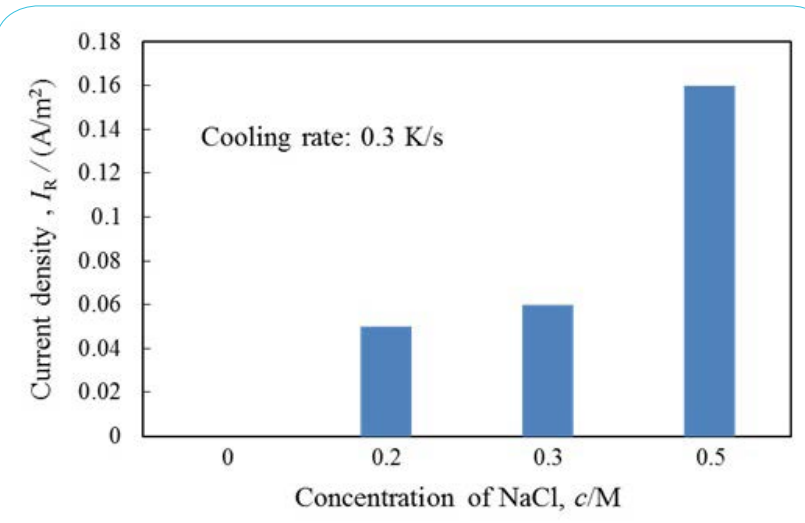

Figure 4 : Reactivation current density $\left(I_{\mathrm{R}}\right)$ obtained from 0.3 and $1.0 \mathrm{~K} / \mathrm{s}$ cooled specimens in solutions of $0.5 \mathrm{M} \mathrm{H}_{2} \mathrm{SO}_{4}+0.01 \mathrm{M} \mathrm{KSCN}+\mathrm{x}(0 \sim$ $0.5) \mathrm{M} \mathrm{NaCl}$ under the condition of SL-EPR (1). 
Citation: Wang R, Imagawa M, Honda M, Fukuhara H (2017) Single Loop Electrochemical Potentiokinetic Reactivation Behaviour of Continuously Cooled SUS329J4L Duplex Stainless Steel. Int J Mech Syst Eng 3: 125. https://doi.org/10.15344/2455-7412/2017/125

Page 4 of 7

attributed to the destruction of passive film and the dissolution from the surroundings of precipitated $\sigma$ phase by the attack of chloride ions $(\mathrm{Cl})$. The reactivation current density in $0.3 \mathrm{M} \mathrm{NaCl}$ (Figure 3c) containing solution is a little larger than that in $0.2 \mathrm{M} \mathrm{NaCl}$ (Figure $3 \mathrm{~b}$ ). Furthermore, the current density obtained in $0.5 \mathrm{M} \mathrm{NaCl}$ containing solution (Figure 3d) is much higher. This result means that the detection sensitivity of SL-EPR is much higher than the modified DL-EPR measurement.

\section{Reactivation current density obtained in $0.5 \mathrm{M} \mathrm{NaCl}$ containing solution}

Figure 5 shows the reactivation current density $\left(I_{\mathrm{R}}\right)$ obtained in $0.5 \mathrm{M} \mathrm{H}_{2} \mathrm{SO}_{4}+0.01 \mathrm{M} \mathrm{KSCN}+0.5 \mathrm{M} \mathrm{NaCl}$ on specimens being cooled at $1.0 \sim 0.1 \mathrm{~K} / \mathrm{s}$. The $I_{\mathrm{R}}$ on $0.02 \mathrm{~K} / \mathrm{s}$ cooled specimen is much higher as $320 \mathrm{~A} / \mathrm{m}^{2}$ (omitted from the figure). Although the precipitated $\sigma$ phase in $0.1 \mathrm{~K} / \mathrm{s}$ cooled specimen should be more than that in the $0.2 \mathrm{~K} / \mathrm{s}$ cooled one according to the previous XRD analysis [23], the value of $I_{R}$ on the former specimen was a little smaller than the latter. This tendency is also like the DL-EPR test. The distinguishing both the reactivation current and the cooling rate is important to cooling process control in the fabrication or the operation conditions for structures and machines. Although the reactivation current can be detected on the $0.3 \mathrm{~K} / \mathrm{s}$ cooled specimen, the distinguishable cooling rate from the value of $I_{\mathrm{R}}$ is between 0.2 and $0.3 \mathrm{~K} / \mathrm{s}$, which is almost the same with previous result obtained from the modified DL-EPR method [23]. On the other hand, the deviation of $I_{\mathrm{R}}$ on the specimen cooled at $0.3 \mathrm{~K} / \mathrm{s}$ is much larger than other, which is the reason for the undistinguishable $I_{\mathrm{R}}$ when comparing to the specimen cooled at $1.0 \mathrm{~K} / \mathrm{s}$. In comparing with DL-EPR test, the polarization time to produce passive film in SL-EPR test until the potential was swept to the reactive potential zone is short. This means that the formation of passive film might be not stable enough. This unstable passive film also corresponded to the larger value and larger deviation of passive current density $\left(I_{\mathrm{p}}\right)$ at $0.3 \mathrm{~V}$ (Figure 2 ) on the specimen being cooled at $0.3 \mathrm{~K} / \mathrm{s}$ (Figure $6 \mathrm{a}$ ). In addition, only on the $0.3 \mathrm{~K} / \mathrm{s}$ cooled specimen occurred the much large deviation of $I_{\mathrm{R}}$ and $I_{\mathrm{p}}$, perhaps there is a special distribution state of $\sigma$ phase in this steel.

\section{Effect of stabilization of passive film}

In order to obtain a stable passive film on specimen surface before sweeping the potential to reactivation zone, a potential holding at 0.3 $\mathrm{V}$ for $300 \mathrm{~s}$ was applied before negative sweep, which is noted as the condition of SL-EPR (2) (Table 2). Such methods were also used to

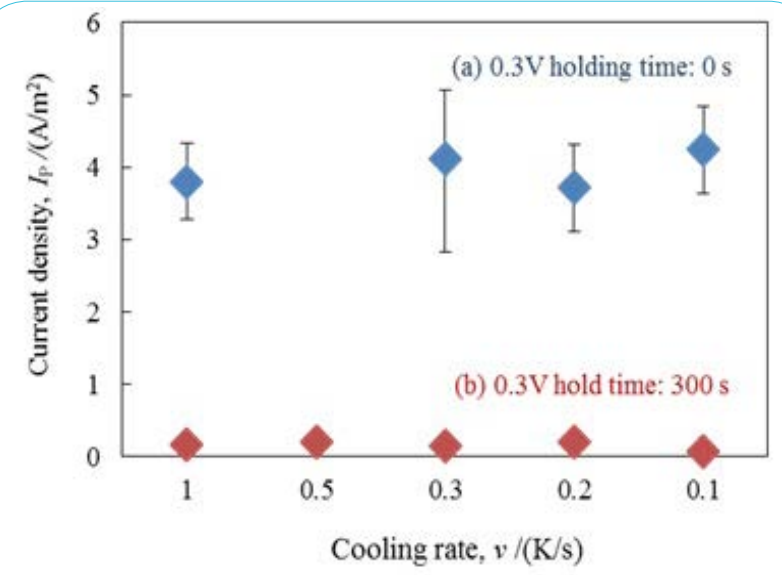

Figure 6: Passive current density $\left(I_{\mathrm{p}}\right)$ obtained from $0.1 \sim 1.0 \mathrm{~K} / \mathrm{s}$ cooled specimens without (a : SL-EPR(1)) and with (b : SL-EPR(2)) $0.3 \mathrm{~V}$ holding for $300 \mathrm{~s}$ in solution of $0.5 \mathrm{M} \mathrm{H}_{2} \mathrm{SO}_{4}+0.01 \mathrm{M} \mathrm{KSCN}+0.5 \mathrm{M}$ $\mathrm{NaCl}$.

investigate the degree of sensitivity in Type 304 and $304 \mathrm{~L}$ steel at $0.2 \mathrm{~V}$ [26] and Inconel 600 at $0.88 \sim 1.0 \mathrm{~V}[29,30]$. The obtained polarization curve with and without the 300-s potential holding is shown in Figure 7 , while the passive current density $\left(I_{\mathrm{p}}\right)$ and the reactivation current density $\left(I_{\mathrm{R}}\right)$ are respectively shown in Figure $6 \mathrm{~b}$ and Figure 8 . As shown in Figure 7, with comparison to without potential holding at $0.3 \mathrm{~V}$, the passive current density at $0.3 \mathrm{~V}$ after potential holding is much lower (Figure 6b) and the further current drop did not occur. This result indicates that a stable passive film had been formed during the 300-s potential holding, which should have reduced both the value of $I_{\mathrm{R}}$ and its deviation. As the result, each value of $I_{\mathrm{R}}$ obtained from $0.3 \sim 1.0 \mathrm{~K} / \mathrm{s}$ cooled specimens become distinguishable, not overlapping each other (Figure 8).

\section{Sigma phase and reactivation current density}

Figure 9 shows the specimen surfaces after polarization under the condition of SL-EPR (2). No obvious $\sigma$ phase can be clearly found at this magnification on either of the surfaces cooled at $1.0 \sim 0.3 \mathrm{~K} / \mathrm{s}$ (Figure $9(\mathrm{a} \sim \mathrm{c})$ ), whereas $\sigma$ phase and the corroded surroundings were observed on the $0.1 \mathrm{~K} / \mathrm{s}$ cooled specimen (Figure $9 \mathrm{~d}$ ). The corroded surroundings should be originated from narrow Cr- or Mo-depleted regions and then perhaps spread to $\gamma^{\prime}$ phase. Therefore, the reactivation current density $I_{\mathrm{R}}$ can be utilized as a sign of the presence of $\sigma$ phase. Except the recognized dissolution from $\mathrm{Cr}$ depleted region, there is also evidence that the active dissolution

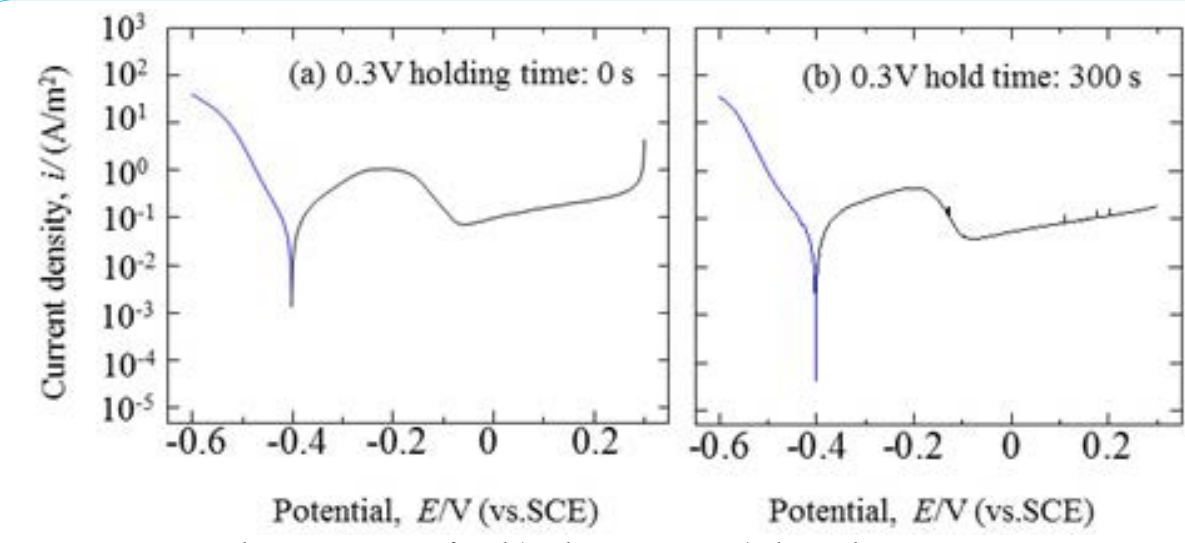

Figure 7: SL-EPR polarization curves of steel (cooling rate: $0.3 \mathrm{~K} / \mathrm{s}$ ) obtained in $0.5 \mathrm{M} \mathrm{H}_{2} \mathrm{SO}_{4}+0.01 \mathrm{M} \mathrm{KSCN}$ $+0.5 \mathrm{M} \mathrm{NaCl}$ solutions without (a: SL-EPR(1)) and with (b: SL-EPR(2)) $0.3 \mathrm{~V}$ holding for $300 \mathrm{~s}$. 
Citation: Wang R, Imagawa M, Honda M, Fukuhara H (2017) Single Loop Electrochemical Potentiokinetic Reactivation Behaviour of Continuously Cooled SUS329J4L Duplex Stainless Steel. Int J Mech Syst Eng 3: 125. https://doi.org/10.15344/2455-7412/2017/125

Page 5 of 7

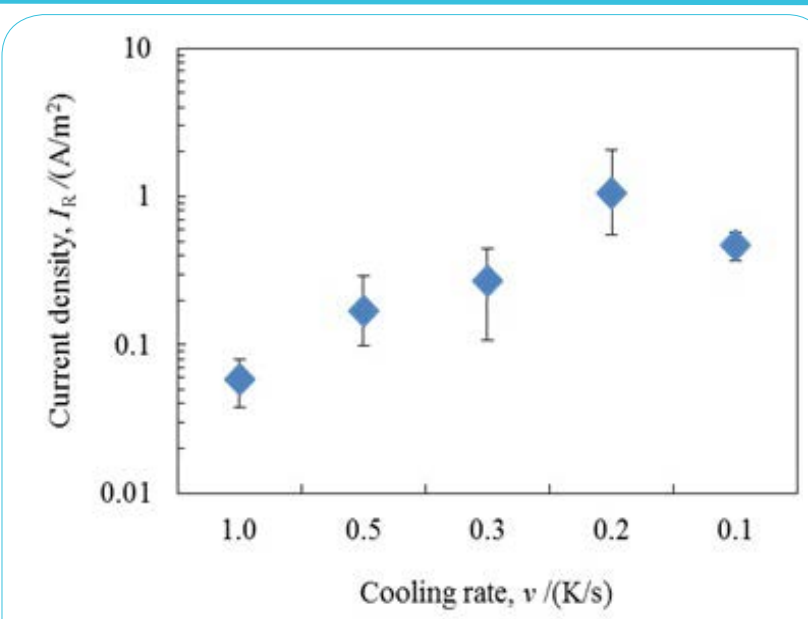

Figure 8 : Reactivation current density $\left(I_{\mathrm{R}}\right)$ obtained from $0.1 \sim 1.0 \mathrm{~K} / \mathrm{s}$ cooled specimens in solution of $0.5 \mathrm{M} \mathrm{H}_{2} \mathrm{SO}_{4}+0.01 \mathrm{M} \mathrm{KSCN}+0.5 \mathrm{M}$ $\mathrm{NaCl}$ under the condition of SL-EPR (2). dissolution from $\gamma / \alpha$ boundaries and $\alpha$ phase (Figure $9 \mathrm{~b}$ and Figure 9c) should be initiated from fine $\sigma$ phase or chromium carbides on the 0.3 and $0.5 \mathrm{~K} / \mathrm{s}$ cooled specimens, considering that the Charpy adsorbed energies were much smaller than the water quenched one. The $\sigma$ phase on the $0.1 \mathrm{~K} / \mathrm{s}$ cooled specimen (Figure $9 \mathrm{~d}$ ) can be also detected in the modified DL-EPR test and the XRD analysis due to the significant precipitation of $\sigma$ phase [23].

\section{Sigma phase and reactivation current density}

Figure 10 shows the SL-EPR current density $I_{\mathrm{R}}$ obtained on specimens cooled at various cooling rates from water quenching (WQ) to $0.02 \mathrm{~K} / \mathrm{s}$ under the condition of SL-EPR (2) in the selected EPR solution of $0.5 \mathrm{M} \mathrm{H}_{2} \mathrm{SO}_{4}+0.01 \mathrm{M} \mathrm{KSCN}+0.5 \mathrm{M} \mathrm{NaCl}$. The results obtained from the ferric chloride test $\left(6.0 \mathrm{wt} . \% \mathrm{FeCl}_{3}\right.$ solution; $24 \mathrm{hrs}$ at $313 \pm 2 \mathrm{~K}$ ), the Charpy impact test (sub-size specimen of (length) $55 \mathrm{x}$ (height) $10 \mathrm{x}$ (width) $7.5 \mathrm{~mm}$ with V-notch at ambient temperature) and the modified DL-EPR ratios (solution: $0.5 \mathrm{M} \mathrm{H}_{2} \mathrm{SO}_{4}$ $+0.01 \mathrm{M} \mathrm{KSCN}+0.5 \mathrm{M} \mathrm{NaCl}$ )[23] are also shown in this figure as
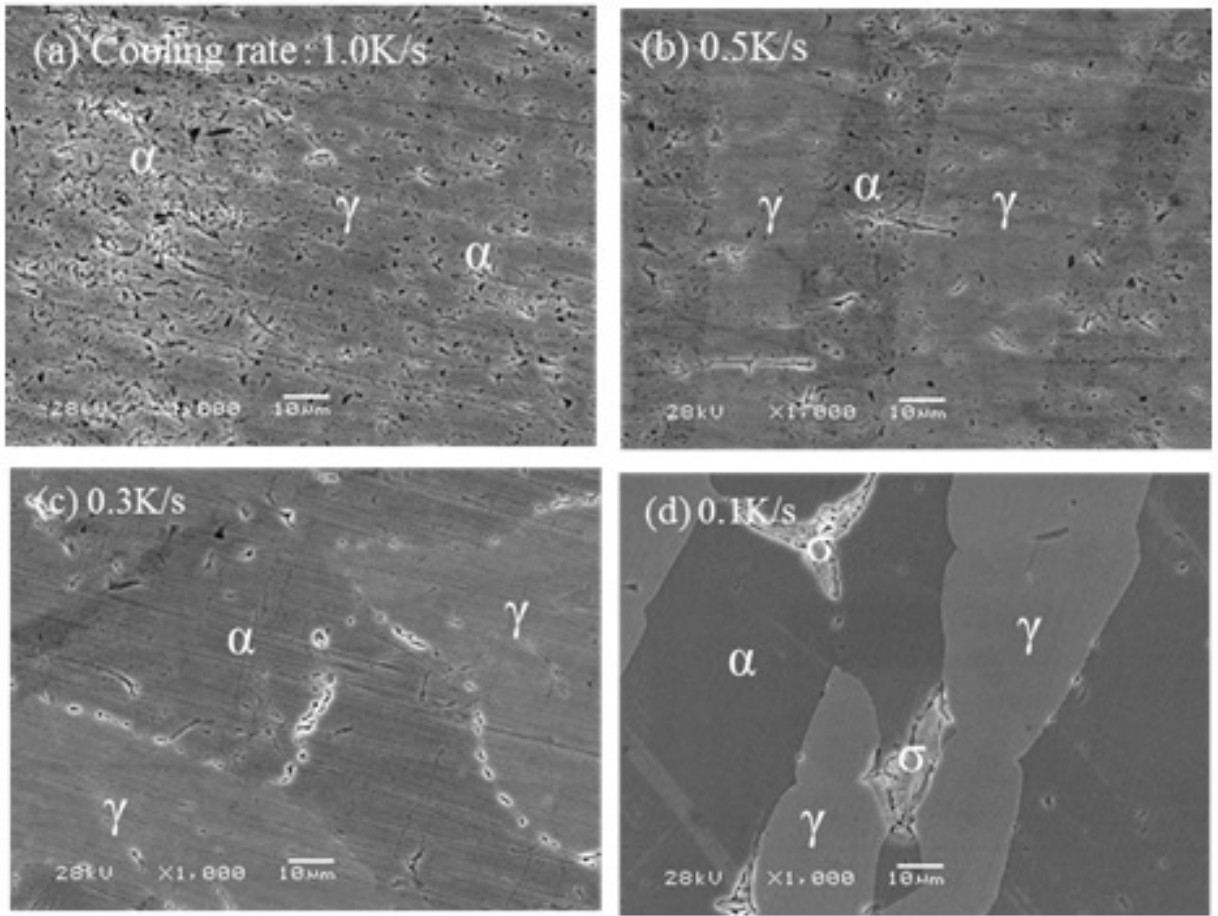

Figure 9 : Specimen surfaces observed after SL-EPR polarization in solution of $0.5 \mathrm{M} \mathrm{H}_{2} \mathrm{SO}_{4}+0.01 \mathrm{M}$ KSCN $+0.5 \mathrm{M} \mathrm{NaCl}$ under the condition of SL-EPR (2). (a) Cooling rate $1.0 \mathrm{~K} / \mathrm{s}$, (b) $0.5 \mathrm{~K} / \mathrm{s}$, (c) $0.3 \mathrm{~K} / \mathrm{s}$ and (d) 0.1 $\mathrm{K} / \mathrm{s}$.

current increases when the content of Mo decreases [28]. With the decrease of cooling rate from 1.0 to $0.3 \mathrm{~K} / \mathrm{s}$, the dissolution varied as (i) dispersive corrosion initiated from both $\gamma$ and $\alpha$ phases without presence of $\gamma / \alpha$ grain boundaries (Figure 9a), (ii) relatively severer corrosion initiated from $\alpha$ phase than from $\gamma$ phase with presence of $\gamma / \alpha$ boundaries (Figure $9 \mathrm{~b}$ ), and (iii) severer localized corrosion from $\gamma / \alpha$ boundaries without corrosion initiated from $\gamma$ phase or $\alpha$ phase (Figure 9c). The dispersive corrosion on $1.0 \mathrm{~K} / \mathrm{s}$ cooled specimen should be triggered by $\mathrm{Cl}^{-}$ions attacking defects in the homogeneous passive film, considering the Charpy adsorbed energy was as large as the water quenched one. Although the reactivation current peak was detected in this case, it cannot be attributed to the precipitation of $\sigma$ phase or chromium carbides. On the other hand, the preferable comparison. On the specimens being cooled at $0.2 \sim 0.02 \mathrm{~K} / \mathrm{s}$, a same variation trend was obtained among all these tests. Obvious differences among specimens can not be found in the ferric chloride test at $1.0 \sim 0.2 \mathrm{~K} / \mathrm{s}$ and in the modified DL-EPR test at $1.0 \sim 0.3 \mathrm{~K} / \mathrm{s}$. However, the SL-EPR current almost kept continuously climbing from 1.0 to $0.02 \mathrm{~K} / \mathrm{s}$. Accordingly, the above modified SL-EPR results can be applied to sensitively detect the presence of $\sigma$ phase in duplex stainless steels, with almost the same sensitivity as the destructive impact test.

When the SL-EPR polarization was applied on ready-made large machines of duplex steel using a portable assembly cell, which can be attached to the machines, it is possible to on-site determine the presence of $\sigma$ phase in the machine. This is helpful to maintain and 


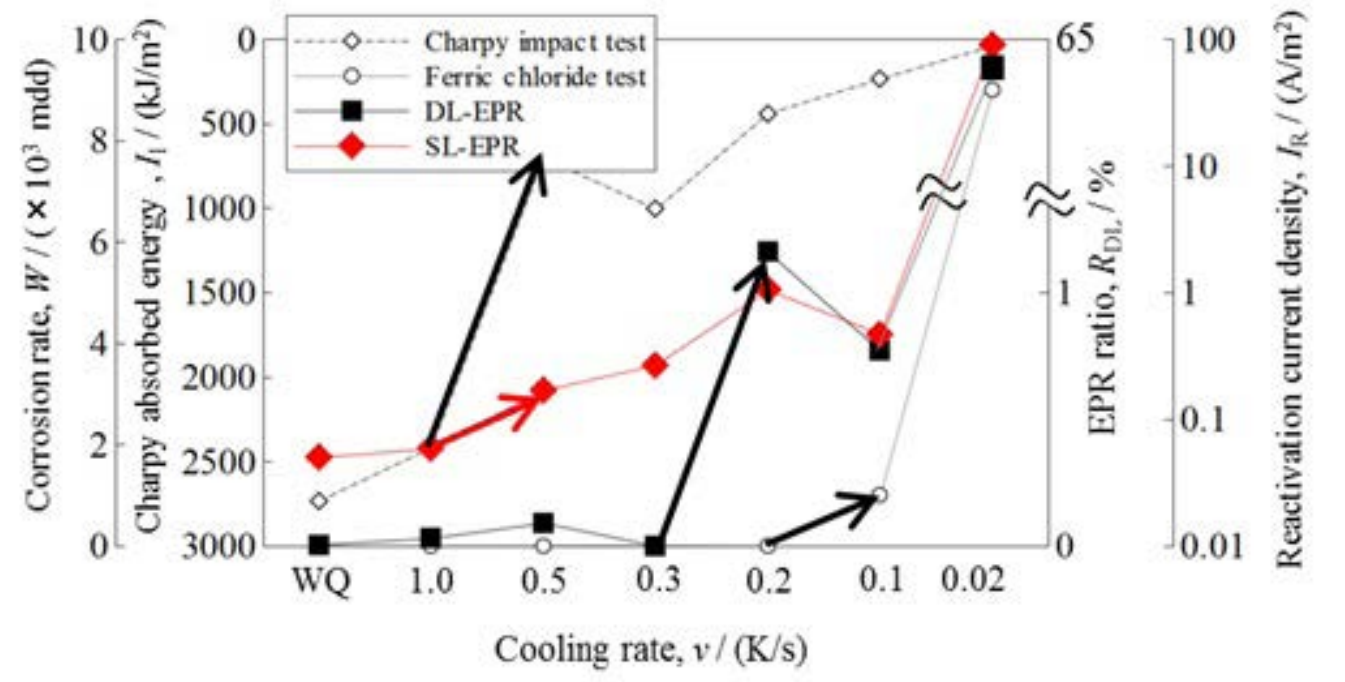

Figure 10 : Comparison of variations of reactivation current densities $\left(I_{\mathrm{R}}\right)$ in SL-EPR $(2)$ test with reactivation ratios $\left(\mathrm{R}_{\mathrm{DL}}\right)$ in DL-EPR test, corrosion rates $(\mathrm{W})$ in ferric chloride test and impact values $\left(I_{\mathrm{I}}\right)$ in Charpy impact test.

enhance the machine's integrity by correctly controlling of the cooling condition. Of course, the detection ability depends on the corrosion from the vicinity to $\mathrm{Cr}$ - or Mo-depleted regions or new $\gamma$ ' phase rather than the $\sigma$ phase itself. Therefore, the reactivation current density varies with either of the shape, the distribution as well as the amount of $\sigma$ phase, which should be clarified in the future work. Moreover, if recovery of $\mathrm{Cr}$ or Mo from adjacent ferrite $(\alpha)$ or new austenite $\left(\gamma^{\prime}\right)$ phase occurs through diffusion in case of long duration of isothermal aging, the variation of SL-EPR reactivation current should be further clarified.

\section{Conclusion}

To on-site detect with high sensitivity the presence of sigma phase precipitated in SUS329J4L duplex stainless steel after continuous cooling, a modified SL-EPR method was applied in comparison with the results from the ferric chloride test, the impact test and the modified DL-EPR polarization. The following results are obtained.

1. The high reactivation current density in the SL-EPR polarization was obtained on the cooled SUS329J4L steel at WQ $\sim 0.02 \mathrm{~K} /$ sin solution of $0.5 \mathrm{M} \mathrm{H}_{2} \mathrm{SO}_{4}+0.01 \mathrm{M} \mathrm{KSCN}+0.5 \mathrm{M} \mathrm{NaCl}$ at potential sweep rate of $0.83 \mathrm{mV} / \mathrm{s}$.

2. The potential holding at $0.3 \mathrm{~V}$ vs. SCE for $300 \mathrm{~s}$ before sweeping the potential to negative side is necessary to stabilize the passive film and thus improved the detection sensitivity of $\sigma$ phase in duplex stainless steel.

3. The modified SL-EPR test which checks the presence of sigma phase has a quasi-equivalent detection sensitivity to impact teston the WQ $\sim 0.02 \mathrm{~K} / \mathrm{s}$ cooled SUS329J4L steel, with higher sensitivity in SL-EPR method than the modified DL-EPR method.

\section{Competing Interests}

The authors declare that there is no competing interest regarding the publication of this article.

\section{Author Contributions}

All authors contributed significantly to this work. Rongguang Wang made substantial contribution to design and guide the experiment, and wrote the manuscript. Masanobu Imagawa performed most of the experiment and analyzed data. Masaharu Honda and Hideki Fukuhara proposed and conceived the study, and gave important advice on understanding the nature of sigma phase precipitation behaviour in duplex stainless steel. All authors participated in drafting the article and revising it critically. All authors read and approved the final manuscript.

\section{References}

1. Nakade K, Kuroda T (2007) Precipitation mechanism of sigma phase in super duplex stainless steels. Journal of High Temperature Society 33: 95100.

2. Kasper JS, Waterstrat RM (1956) Ordering of atoms in the $\sigma$ phase. Acta Cryst 9: 289-295.

3. Dickins GJ, Douglas AMB, Taylor WH (1956) The crystal structure of the Co-Cr $\sigma$ phase. Acta Cryst 9: 297-303.

4. Kumada K (1963) About sigma phase. Bulletin of the Japan Institute of Metals 2: 261-271.

5. Obata E, Itoh K, likubo T (1978) Precipitation behavior of $\sigma$ phase in microduplex stainless steel. Denki Seiko (Electr. Furn. Steel) 49: 242-250.

6. Maehara Y, Koike M, Fujino N, Kunitake T (1981) Precipitation behavior of $\sigma$ Phase in duplex phase stainless steel. Tetsu-to-Hagane 67: 577-586.

7. Chen TH, Weng KL, Yang JR (2002) The effect of high-temperature exposure on the microstructural stability and toughness property in a 2205 duplex stainless steel. Mater Sci Eng A338: 259-270.

8. Hashizume S, Sato K, Honda M, Masamura K, Sakai J, Matsushima (1996) Effect of sigma phase on corrosion resistance of duplex stainless steels. Zairyo-to-kankyo 45: 83-89.

9. Ohmori $Y$, Maehara $Y$ (1984) Precipitaiton of $M_{23} C_{6}$ and $\sigma$-phase in $\delta / Y$ duplex stainless steels. Tetsu-to-Hagane 70: 428-435.

10. Tamura I, Isogami K, Maki T, Fujiwara S (1976) The aging behavior of an Fe-Cr-Ni duplex alloy of ferrite and austenite. J Jpn Inst Met 40: 353-360.

11. Michalska J, Sozańska M (2006) Qualitative and quantitative analysis of $\sigma$ and X phases in 2205 duplex stainless steel. Mater Charact 56: 355-362. 
Citation: Wang R, Imagawa M, Honda M, Fukuhara H (2017) Single Loop Electrochemical Potentiokinetic Reactivation Behaviour of Continuously Cooled SUS329J4L Duplex Stainless Steel. Int J Mech Syst Eng 3: 125. https://doi.org/10.15344/2455-7412/2017/125

Page 7 of 7

12. Kashiwar A, PhaniVennela N, Kamath SL, Khatirkar RK (2012) Effect of solution annealing temperature on precipitation in 2205 duplex stainless steel. Mater Charact 74: 55-63.

13. Chen TH, Yang JR (2001) Effects of solution treatment and continuous cooling on sigma-phase precipitation in a 2205 duplex stainless steel. Mater Sci Eng A311: 28-41.

14. Maehara $\mathrm{Y}$, Fujino N, Kunitake $\mathrm{T}$ (1982) Influence of various factors on the precipitation behavior of sigma phase in duplex phase stainless steel. Tetsu-to-Hagane 68: 673-681.

15. Elshawesh $\mathrm{F}$, Elahresh $\mathrm{N}$, Elhoud A (1998) Effect of $\sigma$ phase on pitting corrosion of 22-5 duplex stainless steel. British Corrosion Journal 33: 285287

16. Ravindranath K, Malhotra SN (1994) Influence of aging on intergranular corrosion of a $25 \%$ chromium $-5 \%$ nickel duplex stainless steel. Corrosion 50: $318-328$

17. Davison RM, Redmond JD (1991) Development of qualification tests for duplex stainless steel mill products. Corrosion 91: The NACE Annual Conference and Corrosion Show.

18. ASTM standard A923-03 (1994) Standard test methods for detecting detrimental intermetallic phase in duplex austenitic / ferritic stainless steels. ASTM International.

19. Fukuhara H, Mori T, Wang R, Imagawa M (2014) Effect of cooling rate on mechanical and corrosion properties of SUS329J4L duplex stainless steel Collected Abstracts of the 57th Meeting of the Chugoku-Shikoku Branch of Iron and Steel Inst. of Japan and 54th Meeting of the Chugoku-Shikoku Branch of Japan Inst. Metals and Materials.

20. Lopez N, Cid M, Puiggali M, Azkarate I, Pelayo A (1997) Application of double loop electrochemical potentiodynamic reactivation test to austenitic and duplex stainless steel. Mater Sci Eng A229: 123-128.

21. Sugiyama M, Kaneko S, Umemura $F$ (1985) Electrochemical method for evaluating the intergranular corrosion susceptibility of stainless steel (JIS draft proposal). Corrosion Engineering 34: 685-691.

22. Číhal V, Štefec R (2001) On the development of the electrochemical potentiokinetic method. Electr Act 46: 3867-3877.

23. Wang R, Imagawa M, Honda M, Mori T, Fukuhara H (2017) Double loop electrochemical potentiokinetic reactivation behaviour of continuously cooled SUS329J4L duplex stainless steel. Corr Eng Sci Tech.

24. Kain V, Watanabe $Y(2002)$ Development of a single loop EPR test method and its relation to grain boundary microchemistry for alloy 600 . Journal of Nuclear Materials 302: 49-59.

25. Leiva-Garcia R, Munoz-Portero MJ, Garcia-Anton J (2011) In-situ study of single and double loop reactivation methods during the characterisation of the degree of sensitisation of a duplex stainless steel (UNS 1.4462) using a minicell and a confocal microscope. Int J Electroche Sci 6: 830-846.

26. ASTM standard G108-94 (2010) Standard test method for electrochemical reactivation (EPR) for detecting sensitization of AISI type 304 and 304L stainless steels. ASTM International.

27. Sieurin H, Sandström R (2007) Sigma phase precipitation in duplex stainless steel 2205. Mater SciEng A444: 271-276.

28. Ito N, Okamoto G (1960) On the Potentiostatic etching of metallographic structure of stainless stee1. J Japan Inst Metals 24: 109-113.

29. Duffaut F, Pouzet JP, Lacombe P (1966) Potentiostatic study of structura modifications caused in a Ni-Cr-Fe alloy by heat treatment at $650{ }^{\circ} \mathrm{C}$. Corrosion Science 6: 83-84

30. Roelandt A, Vereecken J (1986) A modified electrochemical technique (electrochemical potentiokinetic reactivation) for evaluating the susceptibility of Inconel 600 to intergranular corrosion. Corrosion 42: 289-298. 